\title{
1 Facile and green fabrication of cellulosed based aerogels 2 for lampblack filtration from waste newspaper

\section{Abstract:} 100190, China

Peidong Fan, ${ }^{\mathrm{a}}$ Yali Yuan, ${ }^{\mathrm{a}}$ Junkai Ren, ${ }^{\mathrm{a}}$ Bin Yuan,,${ }^{\mathrm{a} b}$ Qian He, ${ }^{\mathrm{a}}$ Guangmei Xia, Fengxia Chen, ${ }^{a}$ Rui Song ${ }^{a^{*}}$

${ }^{a}$ College of Chemistry and Chemical Engineering, University of Chinese Academy of Sciences, Beijing, 100049, China

${ }^{b}$ Beijing National Laboratory for Molecular Sciences, CAS Key Laboratory of Engineering Plastics, Institute of Chemistry, Chinese Academy of Sciences, Beijing,

Corresponding author: rsong@ucas.ac.cn (Rui Song)

*The first two authors contributed equally to this paper.

In this study, the lightweight, hydrophobic and porous cellulose-based aerogels (CAGs) were synthesized through a freeze-drying process using waste newspaper as the only raw material. After crosslinking with glutaraldehyde and treatment with trimethylchlorosilane (TMCS) using a simple thermal chemical vapor deposition process, the resulting CAGs became hydrophobic and oleophilic. Furthermore, the as-prepared CAGs exhibited a low density (17.4-28.7 $\mathrm{mg} \mathrm{cm}^{-3}$ ) and mesoporous inner-structure. All these properties attributed the novel aerogel not only with a good adsorption capability of oils and organic solvents, including kerosene, nitrobenzene, and chloroform, but also an excellent filtration capacity of lampblack.

\section{Keywords: Waste newspaper; Cellulose; Aerogel; Cellulose based aerogel}

*The first two authors contributed equally to this paper. 


\section{Introduction}

26 Inhalation of particulates matter is recognized as the $9^{\text {th }}$ most powerful environmental

27 risk hazard for development and aggravation of diseases, including various lung diseases

28 like asthma and COPD, i.e., chronic obstructive pulmonary disease. (Lim et al., 2012).

29 Recent toxicological (Elsaesser \& Howard, 2012) and epidemiological studies (Meng et

30 al., 2013; Strak et al., 2012) suggest that nanoparticles $\left(\mathrm{D}_{\mathrm{p}} \leq 100 \mathrm{~nm}\right)$ fraction in ambient

31 particulate air pollution is considered as the most harmful component when it comes to

32 pulmonary uptake. They may cause serious health risks because of their high mobility

33 and increased toxicity due to their large specific surface areas. In addition to health

34 concerns, when emitted into the environment, they may potentially lead to new hazard

35 compounds with increased risks to the environment (Maynard \& Pui, 2007; J. Wang, Kim,

36 \& Pui, 2011). Recent experimental data pointed out that oleosols are more pernicious

37 than solid particles. In particular, the lampblack issued from routine cooking cause great

38 concern in populous and developing countries, such as China. A recent study suggested

39 that oil smoke issued from food handling accounts for $16 \%$ of exhaust pollution.

40 (Maynard \& Pui, 2007; Oberdorster, Oberdorster, \& Oberdorster, 2005) To overcome the

41 problem, aerosol filtration process is therefore used in diverse applications, such as air

42 pollution control, reduction of emission, human respiratory protection, and processing of

43 hazardous materials (Hinds, 2012).

44 Another driving force for aerosol filtration processes is the growing necessity of 45 clean air environments utilized by many advanced industries, such as electronics, medical, 46 pharmaceuticals, biological research, gas turbine and nuclear energy installations, 47 automotive applications, among others (P. Tronville \& R. Rivers, 2005; P. Tronville \& R. 
48 D. Rivers, 2005). In regard to this, the filtration of airborne nanoparticles is becoming an 49 important and urgent issue to harness as they are produced in large quantities from 50 several sources, including material synthesis, combustion, emission, and even daily life. 51 HEPA (High-efficiency particulate air Filter) mainly produced from materials like 52 polypropylene filter, glass microfiber, composite PP/PET filter, melt-blown terylene 53 non-woven fabric and melt-blown glass fiber, have been demonstrated to be efficient in 54 reducing the hazards of particulates to health and the environment. However, the high 55 energy consumption, high cost and the elevated emitted pollutes involved in the 56 production of HEPA tremendously limited its wide and sustainable applications.

57 As the most abundant organic polymer, cellulose is regarded as an almost 58 inexhaustible bio-resource, which can be transformed into various useful products. This 59 was witnessed by the numerous investigations performed during the last decade, notably 60 in ultra lightweight cellulose aerogels due to their sustainability, biodegradability and 61 potential applications in fields of tissue engineering, controllable delivery system, blood, 62 and water purification (Ma, Mi, Yu, He, \& Zhang, 2014; Moon, Martini, Nairn, Simonsen, 63 \& Youngblood, 2011). Since its first report in 2001 (Tan, Fung, Newman, \& Vu, 2001), 64 cellulose-based aerogel has attracted extensive interest as a novel kind of green 65 biodegradable nanoporous materials, combined unique features of native cellulose and 66 the excellent properties of traditional silica aerogels, such as ultralow density, high 67 porosity and high specific surface area. To the best of our knowledge, a few of methods, 68 including the critical point drying, directional freeze-casting and freeze-drying (Dash, $\mathrm{Li}$, 69 \& Ragauskas, 2012; Fumagalli, Sanchez, Boisseau, \& Heux, 2013; Heath \& Thielemans, 70 2010), had been employed to prepare the aerogels, whereas distinct deficiency presented, 
71 such as low robustness, low flame retardancy (Moon, Martini, Nairn, Simonsen, \& 72 Youngblood, 2011).

73 Compared to expensive cotton linters and wood pulp, lignocellulose is available in 74 abundant amounts and at low-cost, thus became an attractive alternative. In this respect, 75 the underutilized agricultural wastes, woody biomass, and related resources supply are 76 considered as promising feedstock for cellulose industry. For example, waste newspapers 77 (WNPs), contributing to about 7\% of municipal solid waste, is a typical waste biomass 78 material containing low-cost cellulosic material (Subhedar, Babu, \& Gogate, 2015). In 79 China alone, for example, millions of tons of WNPs are generated annually. Currently, 80 most WNPs are simply used as conventional and low-value products, including recycled 81 newspaper, boxboard, compost, paper insulation, and animal bedding. Therefore, it would 82 be valuable if commonly available biomass resources like WNPs could effectively be 83 employed to prepare high-value cellulose-based materials.

84 During the past years, few attempts were made to prepare cellulose materials from 85 WNPs. Jin et al. (Jin, Han, Li, \& Sun, 2015) successfully prepared cellulose-based 86 aerogels by treating WNPs with trimethylchlorosilane (TMCS). The resulting aerogels 87 exhibited good absorption performance for oils and organic solvents. Using waste 88 newspaper as the only raw materials, Han et al (Han, Sun, Zheng, Li, \& Jin, 2016) 89 synthesized the lightweight, hydrophobic and porous carbon aerogels through 90 freeze-drying and post-pyrolysis processes. The synthesized aerogel showed excellence 91 ability in harvesting organic pollutants, including gasoline and methylbenzene. Recently, 92 Xia et al (Xia et al., 2016) fabricated transparent films from ionic liquid-regenerated 93 WNPs. 
Herein, the lightweight, hydrophobic oleophilic and porous aerogels were fabricated by a freezing-drying method using WNPs as the raw material. After being treated with

PP nonwovens (basis weight $50 \mathrm{~g} / \mathrm{m}^{2}$ ) were provided by Tianjin Teda Co., Ltd. China.

114 HEPA (High efficiency particulate air Filter), AP1101, 3M, US. (CAGs):

Fig.1 present the fabrication process of the cellulose-based aerogel from the waste 
newspapers. The WNPs were pretreated by a series of chemical extraction, in order to remove ink and glue (H. Y. Wang, Li, \& Zhang, 2013). Initially, WNPs were cut into small strips $(1-2 \mathrm{~cm})$ and treated with $2 \mathrm{wt} \%$ sodium hydroxide $(\mathrm{NaOH})$ solution at $90{ }^{\circ} \mathrm{C}$ for $2 \mathrm{~h}$. Subsequently, the samples were cyclically treated using the acidified

122 sodium chlorite $\left(\mathrm{NaClO}_{2}\right)$ solution at $75^{\circ} \mathrm{C}$ for $2 \mathrm{~h}$. Then, the pretreated WNPs $(2 \mathrm{~g})$ were 123 dispersed into the $\mathrm{AmimCl}(18 \mathrm{~g})$, and the dispersion was subject to vigorous mechanical

124

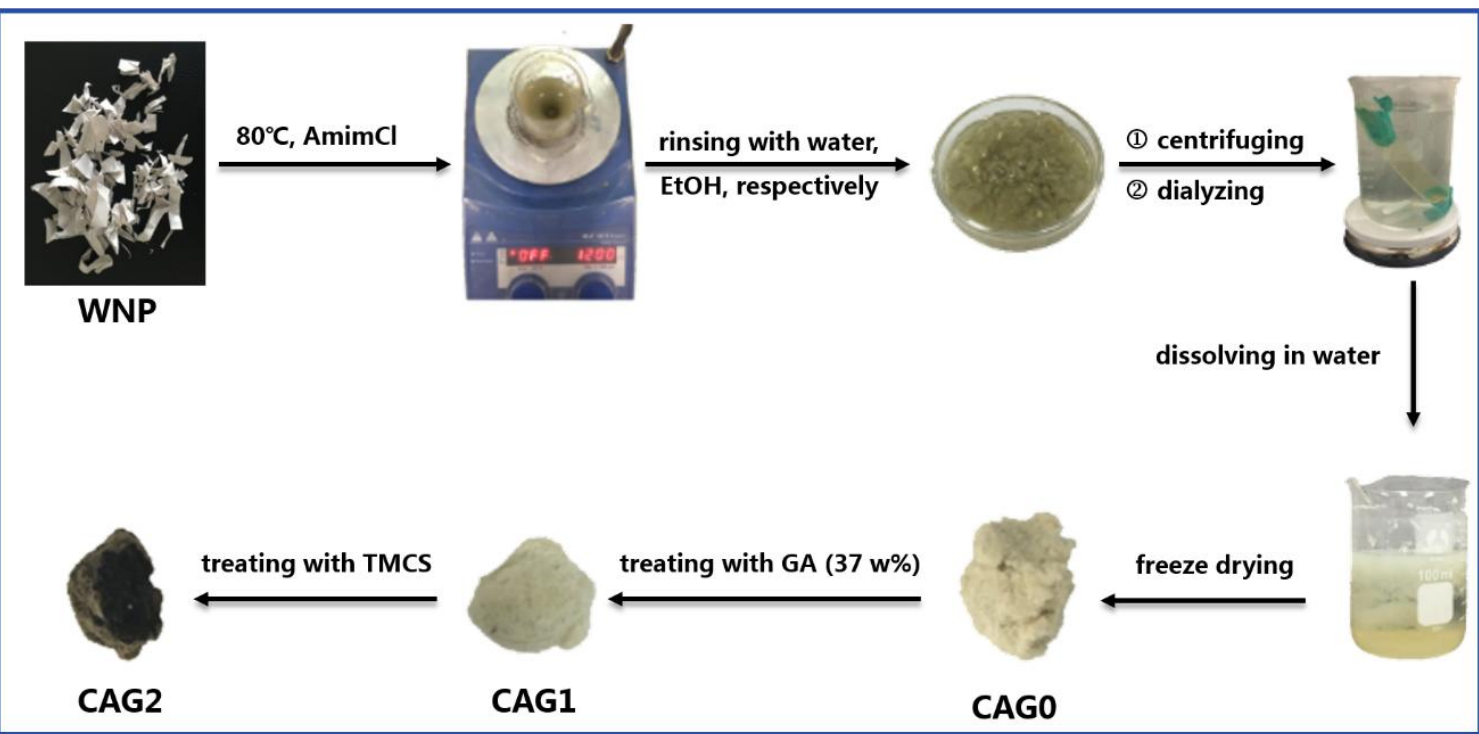

Fig. 1. Schematic illustration of CAGs preparation.

stirring at $80{ }^{\circ} \mathrm{C}$ for $3 \mathrm{~h}$. The resultant was thoroughly rinsed with DI water, ethanol, respectively, for at least 6 times to remove the residual AmimCl completely. For every rinsing step, the dispersion was centrifuged (12000 rpm, $10 \mathrm{~min}$ ) to remove the upper liquid. The gray-green suspension obtained after last centrifugation step was placed inside dialysis membrane tubes (12000-14000 molecular weight cut-off) and dialyzed against slow running DI water for 1-2 days. The membrane tubes containing the extracted cellulose were placed periodically in DI water, and the procedure was continued until a 
neutral $\mathrm{pH}$ was reached. Finally, they were frozen below $-18{ }^{\circ} \mathrm{C}$ and then transferred to a

142 lyophilizer (FD-1CE, Boyikang Co. Ltd., Beijing) with a condenser temperature of $14355^{\circ} \mathrm{C}$ and inside pressure 20-30 Pa. After 2-day lyophilization process CAG0 were 144 obtained.

145 2.3 Preparation of crosslinked CAGs:

146 The resultant CAGs hereinbefore is flexible but fragile. Therefore, to enhance the 147 mechanical robustness, $20 \mathrm{uL} 37 \%$ glutaraldehyde aqueous solution was added dropwise 148 to the regenerated and dialyzed cellulose while stirred in water bath at $50{ }^{\circ} \mathrm{C}$. After 2-day 149 lyophilization, the CAG was obtained. (CAG1, hereinafter).

$150 \quad 2.4$ Hydrophobic modification of CAGs:

151 The hydrophobicity of the CAGs is improved further via the surface silanation 152 reaction procedure as reported by Jin et al. (Jin et al., 2015). Briefly, a small open glass 153 vial containing TMCS (1 mL) was placed in a vacuum desiccator together with CAGs. 154 Then the desiccator was heated and sealed in a vacuum oven at $70{ }^{\circ} \mathrm{C}$ for $12 \mathrm{~h}$ for the 155 silanation reaction. In order to remove the excess amount of unreacted silane and the $\mathrm{HCl}$ 156 byproduct, the coated CAGs were kept in a vacuum desiccator under vacuum for more 157 than $1 \mathrm{~h}(\mathbf{C A G 2}$, hereinafter $)$.

$158 \quad 2.5$ Characterization

159 Density and porosity: The density was calculated by weighting the sample and measuring 160 its volume and the porosity of the sample $(P, \%)$ was calculated by the following 161 equation:

$$
P(\%)=\left(1-\frac{\rho}{\rho *}\right)
$$

163 where $\rho$ is the density of obtained aerogel, $\rho^{*}$ is the skeleton density of cellulose, 
164 which is about $1.59 \mathrm{~g} \mathrm{~cm}^{-3}$ (Heath \& Thielemans, 2010). Each sample was measured in

165 triplicate and the average value was adopted.

166 Sorption of organic solvents and oils by the CAGs: A series of organic reagents and oils

167 were used to study the sorption capacity $\left(Q_{t}, \%\right)$ of the aerogels, and the $Q_{t}$ can be

168 assessed through the following equation:

$169 \quad Q_{\mathrm{t}}=\frac{M_{t}-M_{0}}{M_{0}}$

170 where $m_{t}(\mathrm{~g})$ is the weight of the CAGs after sorption in the selected solvent or oil,

171 and $m_{o}(\mathrm{~g})$ is the initial weight of the CAGs.

172 Powder X-ray diffraction (XRD) data were collected by a Bruker D8-Advance with $173 \mathrm{CuK}_{\alpha}$ radiation $\lambda=0.1542 \mathrm{~nm}$ ) at a scan rate $(2 \theta)$ of $2 \%$ min with the accelerating voltage 174 of $40 \mathrm{kV}$ and the applied current of $30 \mathrm{~mA}$ ranging from $5^{\circ}$ to $40^{\circ}$. Scanning electron 175 microscopy was performed on a field emission SEM (Hitachi S-4800) at an accelerating 176 voltage of $10 \mathrm{kV}$.

177 Fourier transform infrared spectroscopy was carried out on a Nicolet VERTEX 70 178 (Bruker Corp.) spectrometer using the attenuated total reflectance (ATR) method at a 179 resolution of $4 \mathrm{~cm}^{-1}$. The spectra were generated and collected 16 times and corrected for 180 the background noise.

181 Nitrogen physic-sorption measurements were performed by a Quantachrome NOVA 182 2000e at $77 \mathrm{~K}$, and the BET analysis was done for relative vapor pressure from 0.05 to 183 0.3. From the obtained isotherms the BET surface area and the $B J H$ 184 (Barrett-Joyner-Halenda) pore size distribution was calculated from the desorption 185 branch of the isotherm.

186 The filtration efficiency and air flow resistance (pressure drop in $\mathrm{mm} \mathrm{H}_{2} \mathrm{O}$ column 
187 height) were measured by an automated filter tester TSI 8130 (TSI incorporation, 188 Shoreview, MN, US). The tester could deliver neutralized micron monodisperse oil 189 aerosol (with mass median diameter of ca. 0.33 micron, count median diameter of ca. 0.2 $190 \mu \mathrm{m}$, and a geometric standard deviation not exceeding 3.12), and oil aerosols were fed 191 into a filter holder with an effective area of $100 \mathrm{~cm}^{2}$. All filtration tests were conducted 192 with a continuous air flow of $32 \mathrm{l} / \mathrm{min}$ at room temperature. The total aerosol 193 concentration ranges from $10^{6} / \mathrm{cm}^{3}$ to over $10^{8} / \mathrm{cm}^{3}$. Structurally, the tester uses 194 polydispersed oil particles and two photometers to measure total mass concentrations up195 and downstream of the filter. The photometers rely on light scattering from multiple 196 particles to obtain a relative concentration measurement. The signal voltage is 197 proportional to the mass of aerosol sampled by the photometer.

\section{Results and discussion}

Cellulose is a polysaccharide consisting of $\beta-1,4-D$-linked glucose chains, in which the glucose units are joined by single oxygen atoms (acetal linkages between the $\boldsymbol{C}-\boldsymbol{1}$ of a glucose unit and $\boldsymbol{C}-\mathbf{4}$ of the next unit) (Klemm, Heublein, Fink, \& Bohn, 2005). Some of

202 the characteristic IR peaks of cellulose attribution are located at $\sim 900 \mathrm{~cm}^{-1}$ assigned to the $203 \beta$-glucosidic linkage between the glucose units, $\sim 1160 \mathrm{~cm}^{-1}$ of $\mathrm{C}-\mathrm{O}$ symmetric stretching 204 of primary ethanol, and $2900 \mathrm{~cm}^{-1}$ attributed to stretching vibration of C-H stemmed 205 from the $\mathrm{CH}_{2}$ group.
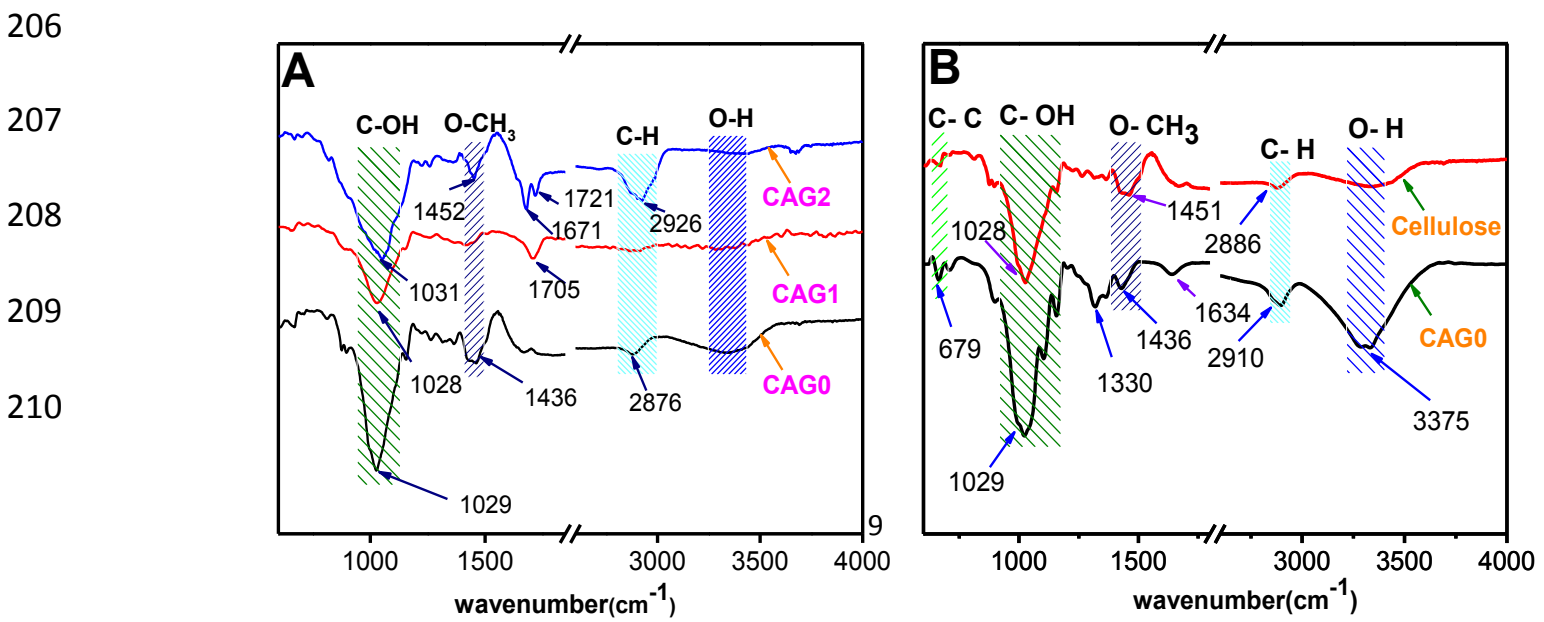
213 Fig. 2. FTIR spectra of the CAG0, CAG1 and CAG2 (A), and comparative FTIR spectra 214 of CAG0 and neat cellulose.

215 As shown in the FTIR spectra, the dissolution and subsequent regeneration induced a 216 broadening and shifting of the peaks towards higher wavenumbers, particularly the 217 characteristic absorption band of $\mathrm{O}-\mathrm{H}$ stretching vibration located at $~ 3343 \mathrm{~cm}^{-1}$ (Fig. 218 2A). This implied the AmimCl-induced breakage of the hydrogen bonds in the 219 preparation of the cellulose-based aerogels (F. C. Wang, Feve, Lam, \& Pascault, 1994). It 220 is noteworthy that, comparing with the neat cellulose, the absence of the semicellulose 221 indicative $\left(\sim 1634 \mathrm{~cm}^{-1}, \mathrm{C}=\mathrm{O}\right.$ stretching vibration $)$ and the lignin indicative $\left(\sim 1661 \mathrm{~cm}^{-1}\right.$, $222 \sim 1622 \mathrm{~cm}^{-1}$, all $\mathrm{C}=\mathrm{O}$ stretching vibration )suggest all three aerogels are comprised mostly 223 of cellulose (Fig. 2B) (Cao, Li, Zhang, Zhang, \& He, 2010; Himmelsbach, Khalili, \& 224 Akin, 2002; Kaparaju \& Felby, 2010). Moreover, the weakening and downshifting of the $225 \sim 1451 \mathrm{~cm}^{-1}$ band indicated that there was a crystal form transformation (from cellulose I 226 to cellulose II) during the dissolution and regeneration process (Oh et al., 2005). For 227 crosslinking aerogel CAG1, $\sim 1705 \mathrm{~cm}^{-1}$ was assigned to the characteristic absorption 228 band for glutaraldehyde; however, the same assignment was appeared at $\sim 1671 \mathrm{~cm}^{-1}$ and $229 \sim 1621 \mathrm{~cm}^{-1}$ for CAG2. For hydrophobically modified CAG2, a series of strong peaks 230 appeared at $\sim 798 \mathrm{~cm}^{-1}, \sim 1257 / 1436 \mathrm{~cm}^{-1}$ and $\sim 2926 \mathrm{~cm}^{-1}$. These peaks were attributed to 231 the Si-O symmetrical stretching, methylene's symmetric/or asymmetric bending, and 232 methylene's stretching vibration, respectively (Xia et al., 2016).

233 In order to figure out the crystalline phases, the aerogels were analyzed by X-ray 
234 diffraction and the results are shown in Fig. 3. The XRD profile of CAG0 exhibited a

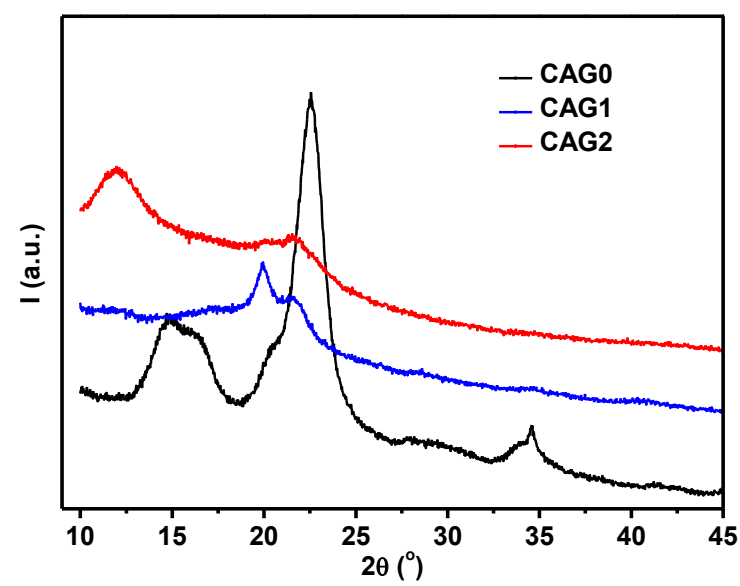

235

236 Fig. 3. XRD curves of CAG0, CAG1 and CAG2.

237

238 distinct peak at $2 \theta=22.2^{\circ}$, corresponding to the (002) lattice planes of cellulose $\mathrm{I}$.

239 Moreover, two overlapping peaks at $2 \theta=14.0^{\circ} \sim 17.8^{\circ}$, corresponding to the (101) and

240 (10i ) lattice planes of cellulose I crystalline structure could be noticed (Zheng, Cai, Ma,

$241 \&$ Gong, 2015). On the other hand, the XRD profile of CAG1 and CAG2 displayed broad

242 peaks ranging from $20^{\circ}$ to $21.5^{\circ}$, stemmed from overlapped two peaks of cellulose II

243 centered at $20.1^{\circ}(110)$ and $21.9^{\circ}(200)$, as well as the amorphous cellulose peak at $\sim 17.3^{\circ}$

244 (Oh et al., 2005). For CAG1, a small but well-resolved peak located at $\sim 20^{\circ}$ assigned to

245 (102) diffraction was also noticed (Morandi, Heath, \& Thielemans, 2009). It is

246 noteworthy that for CAG2, the distinct peak located at $\sim 12.0^{\circ}(2 \theta)$ was attributed to the

247 lattice planes of $\mathrm{SiO}_{2}$ inorganic additives (Xia et al., 2016). 

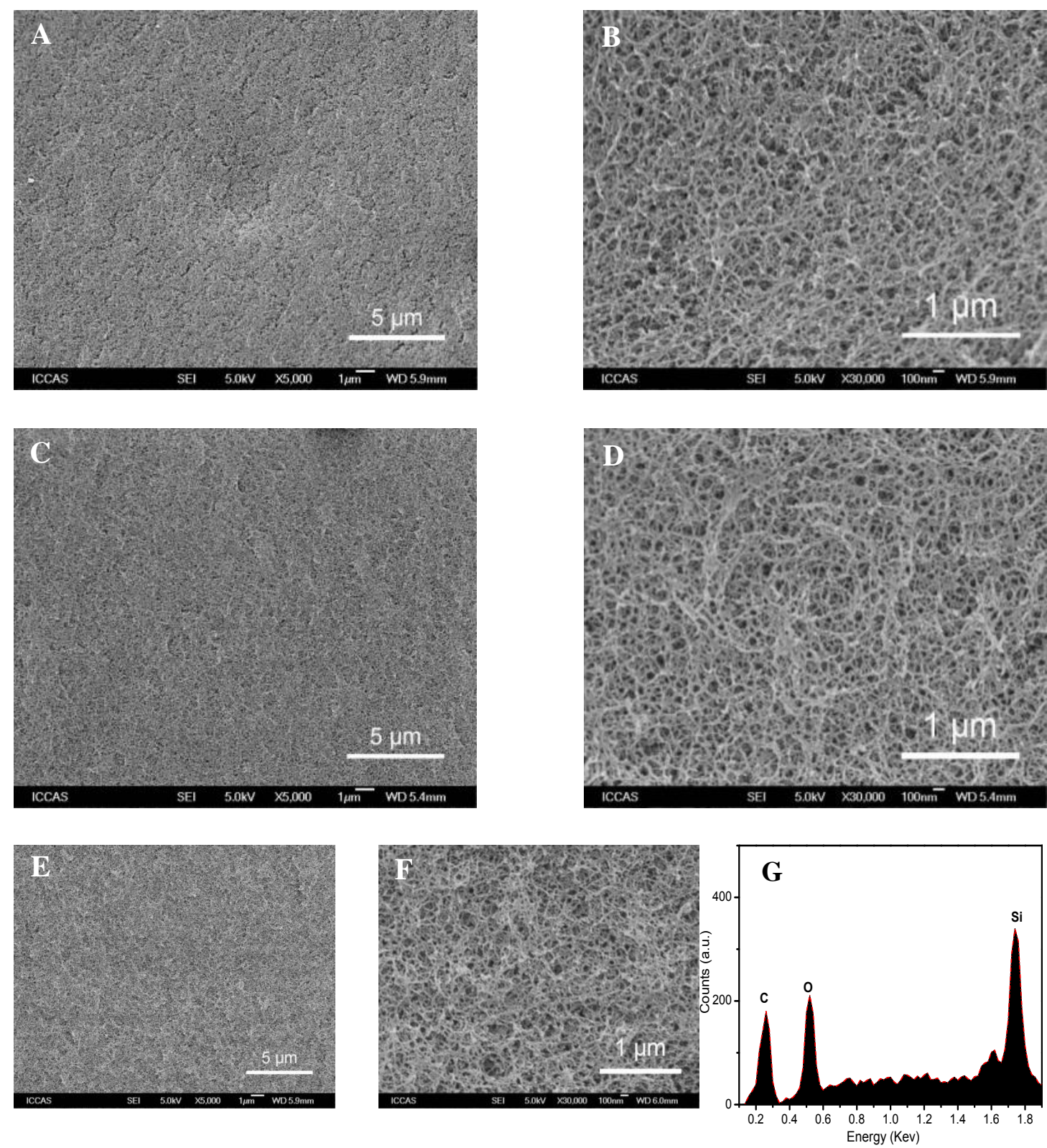

249 Fig. 4. SEM images with low $(\times 5000)$ and high magnification $(\times 30000)$ of CAGs. (A-B)

250 CAG0; (C-D) CAG1 and (E-F) CAG2. EDS element mapping of CAG2 which clearly

251 demonstrated the silicon element.

252

The SEM images of the aerogels are shown in Fig. 4. At both low $(\times 5000)$ and high 254 magnification $(\times 30000)$, the aerogels showed smooth morphology with no obvious 
255 distinguished difference. In other words, all samples exhibited interconnected, highly 256 porous and nanofiber-like structure. This implied that the dissolution, subsequent 257 regeneration, and even the hydrophobic modification, was failed to bring about a 258 detectable influence on microstructure of the cellulose aerogel. For TMCS modified 259 CAG-2, the presence of a signal of silicon element (ca. 1.74 Kev) (Fig. 4G) demonstrated 260 its incorporation in the composite matrices, which is well consistent with the FTIR data.

261 The internal structure of the aerogel samples was characterized by $\mathrm{N}_{2}$ 262 adsorption/desorption experiments (Fig. 5). The isotherms shape points of neat cellulose 263 aerogel, CAG0, and modified aerogels CAG1 and CAG2 could be categorized to type IV 264 character according to the IUPAC classification with a small hysteresis loop (Fig. 5A). 265 This may suggest that the mesoporous structures of the obtained aerogels and the $\mathrm{N}_{2}$ 266 hysteresis have some pore blocking and percolation within the porous network 267 (Shopsowitz, Hamad, \& MacLachlan, 2011).
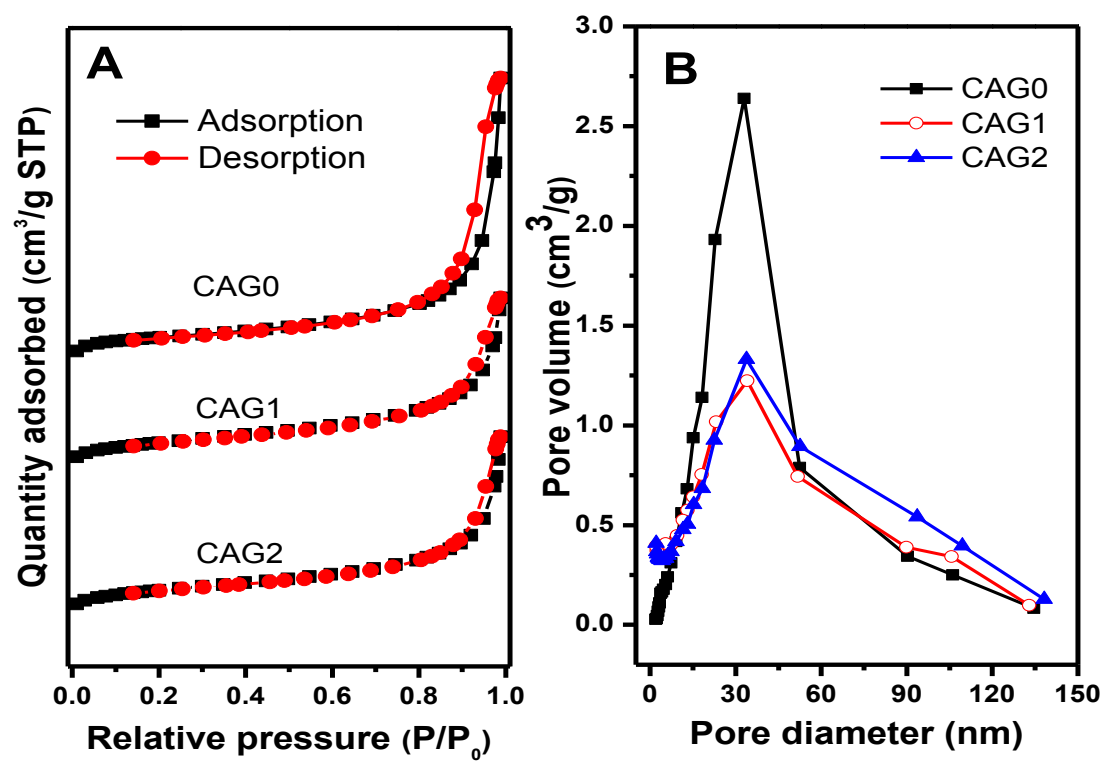
269 Fig. 5. Nitrogen adsorption/desorption isotherms (A) and Barrett-Joyner-Halenda (BJH)

270 pore-size distribution (B) of neat cellulose aerogel, CAG0, and CAG1, CAG2 calculated

271 from the desorption branch of the isotherm.

272 The estimated average density $\left(\mathrm{mg} \mathrm{cm}^{-3}\right)$ of the CAGs varied from 17.36 to 28.68,

273 consistent with densities reported for other cellulose aerogels (Heath \& Thielemans, 2010;

274 Liebner et al., 2010). On the other hand, the porosity decreased slightly as the density

275 increased (Table 1). In addition, the amount of nitrogen adsorbed between 0.05 and 0.3

276 was utilized to calculate the BET surface area with the assumption of adsorbed monolayer.

277 Interestingly, the values of BET surface areas of CAG1 and CAG2 were greater than that

278 of CAG0, while the pore volume of CAG0 was slightly larger when compared to those of

279 CAG1 and CAG2 (Fig. 5B and Table 1). The distribution of pore size calculated from

280 the desorption branch of the isotherm using Barrett-Joyner-Halenda (BJH) model yielded

281 pore sizes ranging from $8 \mathrm{~nm}$ to $13 \mathrm{~nm}$ with the following order: CAG0 $>$ CAG1 $>\mathrm{CAG} 2$

282 (Fig. 5B).

Table 1 Characteristic parameters for CAGs

\begin{tabular}{cccccc}
\hline Sample & $\begin{array}{c}\text { Density } \\
\left(\mathrm{mg} \mathrm{cm}^{-3}\right)\end{array}$ & $\begin{array}{c}\text { Porosity } \\
(\%)\end{array}$ & $\begin{array}{c}S_{\mathrm{BET}} \\
\left(\mathrm{m}^{2} \mathrm{~g}^{-1}\right)\end{array}$ & $\begin{array}{c}\text { Pore volume } \\
\left(\mathrm{cm}^{3} \mathrm{~g}^{-1}\right)\end{array}$ & $\begin{array}{c}\text { Pore size } \\
(\mathrm{nm})\end{array}$ \\
\hline CAG0 & 17.4 & 98.9 & 296 & 0.97 & 13.1 \\
CAG1 & 23.1 & 98.5 & 412 & 0.78 & 7.6 \\
CAG2 & 28.7 & 98.2 & 405 & 0.82 & 8.1 \\
\hline
\end{tabular}

After glutaraldehyde crosslinking and crosslinking/TMCS treated simultaneously, the

286 CAG1 and CAG2 displayed enhanced mechanical properties (in strength and modulus)

287 and hydrophobicity comparing with the CAG0 (Fig. 6). Specifically, the CAG2 indicates

288 a water contact angle of ca.135 , which is markedly higher than that of CAG0 and CAG1.

289 The lightweight, porous structure and the excellent hydrophobicity/oleophilicity of CAG 

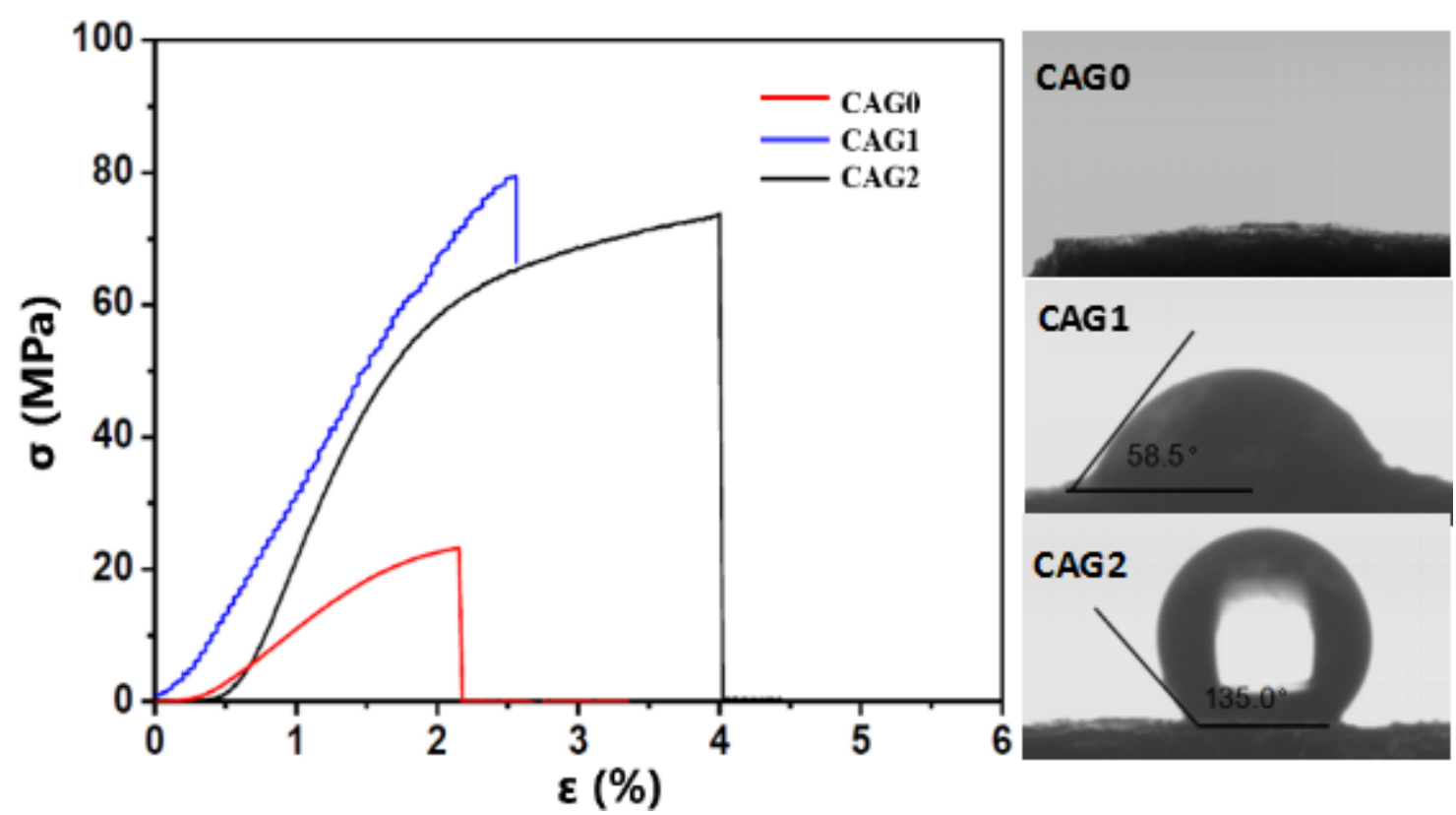

299

Fig. 6. The stress-strain curves (A) and water contact angles (B) of CAG0, CAG1 and 300 CAG2.

make it an ideal candidate for highly efficient separation/extraction of organic pollutants and oils. In order to quantitatively assess the sorption capacity of CAGs, the weight gain (wt\%) was defined as the weight of absorbed substances per unit weight of the original

CAGs. A series of organic solvents and oils were investigated, including chloroform, benzene, nitrobenzene, as well as some commercial oils, such as kerosene, gasoline, lubricant, used engine oil, and soybean oil. When compared to CAG0, the crosslinked and chemically modified CAG2 exhibited an outstanding sorption property, with weight gain as high as 2600-4500 wt\% (Fig. 7). Obviously, CAG2 exhibited a rather high absorption capacity of all investigated oils and organic solvents. 


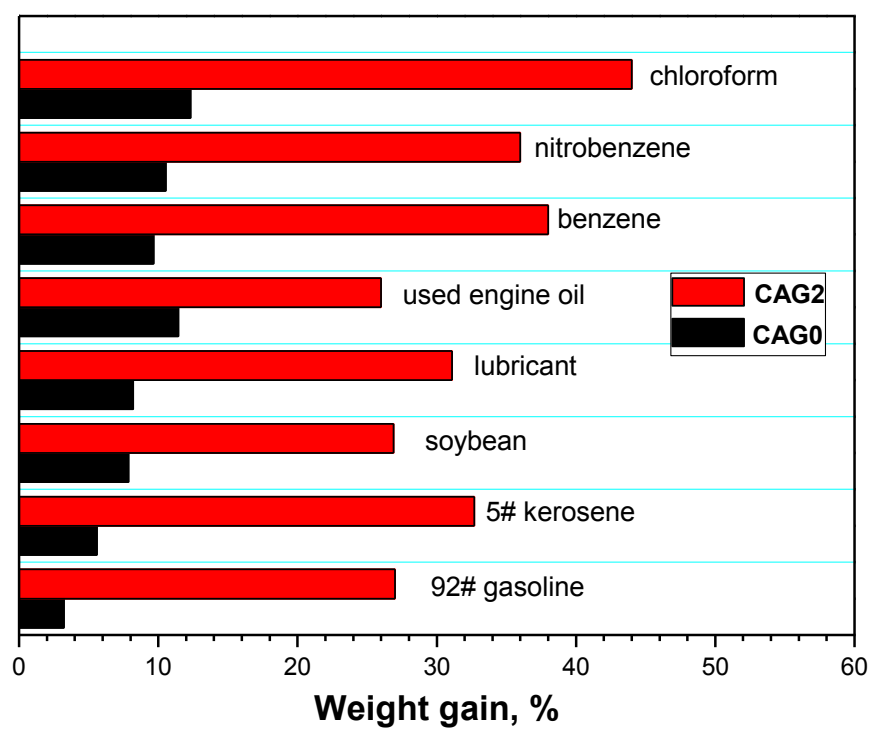

323 Fig. 7. Sorption capacity of CAGs for oils and various organic solvents. The tests are 324 performed with a duration of $1 \mathrm{~min}$ in the selected solvents or oils at room temperature $325\left(22^{\circ} \mathrm{C}\right)$.

326 In addition to its excellent sorption capability towards organic pollutants and oils, the 327 resulting CAGs also displayed a good filtration performance. As a proof of concept, the 328 total mass concentrations up- and downstream of the filter were examined using 329 polydispersed oil particles. As shown in Fig.8, all CAGs exhibited better filtration 330 performance than PP nonwovens in term of filtration efficiency (\%). CAG2 showed a 


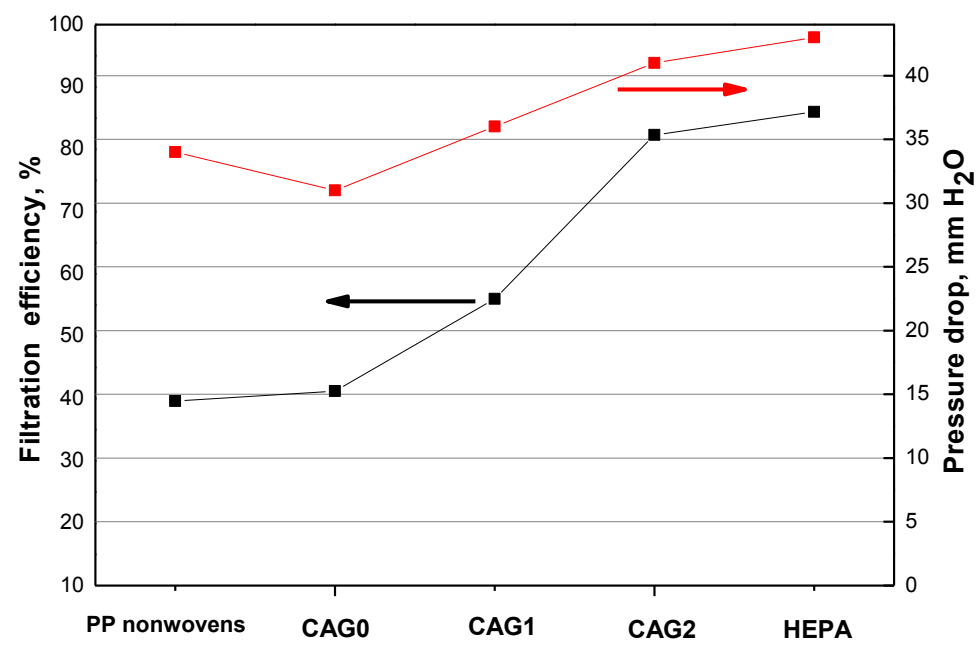

344 Fig. 8. The filtration performance of PP nonwovens, HEPA and three kinds of cellulose 345 based aerogels, CAG0, CAG1 and CAG2.

347 filtration efficiency of about $82.4 \%$, which was comparable to that of HEPA filter 348 ( $86.3 \%)$. Meanwhile, the CAGs possessed lower pressure drop (ca. 32.4-41.6 $\mathrm{mm} \mathrm{H}_{2} \mathrm{O}$ ) 349 as compared to that of HEPA filter $\left(\sim 44.0 \mathrm{~mm} \mathrm{H}_{2} \mathrm{O}\right)$. The filtration efficiency and 350 pressure drop are key parameters of fibrous filters, and a combination of high filtration 351 efficiency with low-pressure drop is an indication of a good filter (Jiao et al., 2015; Li, 352 Wang, Zhang, \& Wei, 2014).

4. Conclusions

354 A lightweight, hydrophobic and porous cellulose-based aerogels (CAGs) were 355 successfully synthesized through freeze-drying process of waste newspaper as the only 356 raw materials utilized instead of cost prohibitive and high-grade pulp. With further 357 crosslinking with glutaraldehyde and surface treatment using trimethylchlorosilane under 358 simple vapor deposition process, the resulting CAGs were bestowed with enhanced 
robustness, hydrophobic, and oleophilic properties.

Systematic characterizations yielded more insights about the (inner-) structure and

the fabrication route. The nitrogen sorption/desorption analysis revealed mesoporous structures of the obtained aerogels with pore sizes ranging from 8-13 nm, while XRD and FITR measurements showed a crystal form transformation from cellulose I to cellulose II during the dissolution and regeneration processes. The resulting aerogels presented not only prominent adsorption for oils and organic solvents, but also exhibited excellent filtration capacity comparable to that of HEPA membrane for lampblack. Therefore, this study provided a simple, cost-efficient, and scalable method for fabricating highly

flexible with elevated performance aerogels based on abundant natural cellulose.

369

\section{Acknowledgements}

This work was supported by the National Science Foundation of China (21072221, 21172252). We also acknowledge Dr. Yan Liu, from the Academy of Environmental Science, Beijing for the help on the test of filter property; and Mr. Xiao Wu, Prof. Wei Huang, from the Institute of Chemistry, Chinese Academy of Sciences (CAS), for the help on the XPS measurements.

\section{References and notes}

Cao, Y., Li, H. Q., Zhang, Y., Zhang, J., \& He, J. S. (2010). Structure and Properties of Novel Regenerated Cellulose Films Prepared from Cornhusk Cellulose in Room Temperature lonic Liquids. Journal of Applied Polymer Science, 116(1), 547-554.

Dash, R., Li, Y., \& Ragauskas, A. J. (2012). Cellulose nanowhisker foams by freeze casting. Carbohydrate Polymers, 88(2), 789-792.

Elsaesser, A., \& Howard, C. V. (2012). Toxicology of nanoparticles. Advanced Drug Delivery Reviews, 64(2), 129-137.

Fumagalli, M., Sanchez, F., Boisseau, S. M., \& Heux, L. (2013). Gas-phase esterification of cellulose nanocrystal aerogels for colloidal dispersion in apolar solvents. Soft Matter, 9(47), 11309-11317.

Han, S. J., Sun, Q. F., Zheng, H. H., Li, J. P., \& Jin, C. D. (2016). Green and facile fabrication of carbon aerogels from cellulose-based waste newspaper for solving organic pollution. Carbohydrate 
Polymers, 136, 95-100.

Heath, L., \& Thielemans, W. (2010). Cellulose nanowhisker aerogels. Green Chemistry, 12(8), 1448-1453.

Himmelsbach, D. S., Khalili, S., \& Akin, D. E. (2002). The use of FT-IR microspectroscopic mapping to study the effects of enzymatic retting of flax (Linum usitatissimum L) stems. Journal of the Science of Food and Agriculture, 82(7), 685-696.

Hinds, W. C. (2012). Aerosol Technology: Properties, Behavior, and Measurement of Airborne Particles, 2nd Edition.

Jiao, K. Y., Zhu, T., Li, X. H., Shan, M. J., Xu, Z. W., \& Jiao, Y. N. (2015). Assembly of graphene oxide on nonconductive nonwovens by the synergistic effect of interception and electrophoresis. Journal of Nanoparticle Research, 17(9), 15.

Jin, C. D., Han, S. J., Li, J. P., \& Sun, Q. F. (2015). Fabrication of cellulose-based aerogels from waste newspaper without any pretreatment and their use for absorbents. Carbohydrate Polymers, 123, 150-156.

Kaparaju, P., \& Felby, C. (2010). Characterization of lignin during oxidative and hydrothermal pre-treatment processes of wheat straw and corn stover. Bioresource Technology, 101(9), 3175-3181.

Klemm, D., Heublein, B., Fink, H. P., \& Bohn, A. (2005). Cellulose: Fascinating biopolymer and sustainable raw material. Angewandte Chemie-International Edition, 44(22), 3358-3393.

Li, P., Wang, C. Y., Zhang, Y. Y., \& Wei, F. (2014). Air Filtration in the Free Molecular Flow Regime: A Review of High-Efficiency Particulate Air Filters Based on Carbon Nanotubes. Small, 10(22), 4543-4561.

Liebner, F., Haimer, E., Wendland, M., Neouze, M. A., Schlufter, K., Miethe, P., . . Rosenau, T. (2010). Aerogels from Unaltered Bacterial Cellulose: Application of $\mathrm{scCO}(2)$ Drying for the Preparation of Shaped, Ultra-Lightweight Cellulosic Aerogels. Macromolecular Bioscience, 10(4), 349-352.

Lim, S. S., Vos, T., Flaxman, A. D., Danaei, G., Shibuya, K., Adair-Rohani, H., . . Ezzati, M. (2012). A comparative risk assessment of burden of disease and injury attributable to 67 risk factors and risk factor clusters in 21 regions, 1990-2010: a systematic analysis for the Global Burden of Disease Study 2010. Lancet, 380(9859), 2224-2260.

Ma, S. R., Mi, Q. Y., Yu, J., He, J. S., \& Zhang, J. (2014). Aerogel Materials Based on Cellulose. Progress in Chemistry, 26(5), 796-809.

Maynard, A. D., \& Pui, D. Y. H. (2007). Nanotechnology and occupational health: Springer.

Meng, X., Ma, Y. J., Chen, R. J., Zhou, Z. J., Chen, B. H., \& Kan, H. D. (2013). Size-Fractionated Particle Number Concentrations and Daily Mortality in a Chinese City. Environmental Health Perspectives, 121(10), 1174-1178.

Moon, R. J., Martini, A., Nairn, J., Simonsen, J., \& Youngblood, J. (2011). Cellulose nanomaterials review: structure, properties and nanocomposites. Chemical Society Reviews, 40(7), 3941-3994.

Morandi, G., Heath, L., \& Thielemans, W. (2009). Cellulose Nanocrystals Grafted with Polystyrene Chains through Surface-Initiated Atom Transfer Radical Polymerization (SI-ATRP). Langmuir, 25(14), 8280-8286.

Oberdorster, G., Oberdorster, E., \& Oberdorster, J. (2005). Nanotoxicology: An emerging discipline evolving from studies of ultrafine particles. Environmental Health Perspectives, 113(7), 823-839.

Oh, S. Y., Yoo, D. I., Shin, Y., Kim, H. C., Kim, H. Y., Chung, Y. S., . . Youk, J. H. (2005). Crystalline structure analysis of cellulose treated with sodium hydroxide and carbon dioxide by means of $\mathrm{X}$-ray diffraction and FTIR spectroscopy. Carbohydrate Research, 340(15), 2376-2391.

Shopsowitz, K. E., Hamad, W. Y., \& MacLachlan, M. J. (2011). Chiral Nematic Mesoporous Carbon Derived From Nanocrystalline Cellulose. Angewandte Chemie-International Edition, 50(46), 10991-10995.

Strak, M., Janssen, N. A. H., Godri, K. J., Gosens, I., Mudway, I. S., Cassee, F. R., . . . Hoek, G. (2012). Respiratory Health Effects of Airborne Particulate Matter: The Role of Particle Size, Composition, and Oxidative Potential-The RAPTES Project. Environmental Health Perspectives, 120(8), 1183-1189.

Subhedar, P. B., Babu, N. R., \& Gogate, P. R. (2015). Intensification of enzymatic hydrolysis of waste newspaper using ultrasound for fermentable sugar production. Ultrasonics Sonochemistry, 22, 326-332.

Tan, C. B., Fung, B. M., Newman, J. K., \& Vu, C. (2001). Organic aerogels with very high impact strength. Advanced Materials, 13(9), 644-646. 
Tronville, P., \& Rivers, R. (2005). International standards : filters for buildings and gas turbines. Filtration \& Separation, 42(7), 39-+.

Tronville, P., \& Rivers, R. D. (2005). International standards: filters for vehicular applications. Filtration \& Separation, 42(9), 24-27.

Wang, F. C., Feve, M., Lam, T. M., \& Pascault, J. P. (1994). FTIR ANALYSIS OF HYDROGEN-BONDING IN AMORPHOUS LINEAR AROMATIC POLYURETHANES .1. INFLUENCE OF TEMPERATURE. Journal of Polymer Science Part B-Polymer Physics, 32(8), 1305-1313.

Wang, H. Y., Li, D. G., \& Zhang, R. R. (2013). Preparation of Ultralong Cellulose Nanofibers and Optically Transparent Nanopapers Derived from Waste Corrugated Paper Pulp. Bioresources, 8(1), 1374-1384.

Wang, J., Kim, S. C., \& Pui, D. Y. H. (2011). Carbon Nanotube Penetration through a Screen Filter: Numerical Modeling and Comparison with Experiments. Aerosol Science and Technology, 45(3), 443-452.

Xia, G., Wan, J., Zhang, J., Zhang, X., Xu, L., Wu, J., . . Zhang, J. (2016). Cellulose-based films prepared directly from waste newspapers via an ionic liquid. Carbohydrate Polymers, 151, 223-229.

Zheng, Q. F., Cai, Z. Y., Ma, Z. Q., \& Gong, S. Q. (2015). Cellulose Nanofibril/Reduced Graphene Oxide/Carbon Nanotube Hybrid Aerogels for Highly Flexible and All-Solid-State Supercapacitors. Acs Applied Materials \& Interfaces, 7(5), 3263-3271. 